\title{
Um panorama do mercado de trabalho da pessoa com deficiência visual na cidade do Rio de Janeiro
}

\author{
An overview of the labor market of people with visual impairment in \\ Rio de Janeiro
}

\section{Una visión general del mercado laboral para personas con discapacidad visual en la ciudad de Rio de Janeiro}

\author{
Meline Melegario Lima ${ }^{1}$ \\ Kátia Eliane Santos Avelar ${ }^{1}$ \\ José Teixeira de Seixas Filho ${ }^{1}$ \\ Patricia Maria Dusek ${ }^{1}$
}

Recebido em 03/12/2019; revisado e aprovado em 21/03/2020; aceito em 17/07/2020

DOI: http://dx.doi.org/10.20435/inter.v22i1.2835

\begin{abstract}
Resumo: O artigo tem o objetivo de traçar o perfil de uma amostra da população com deficiência (PcD), especificamente a deficiência visual, e de empresas do setor privado que contratam PcD na cidade do Rio de Janeiro, visando obter subsídios para a melhoria de políticas públicas que garantam a este grupo social o direito de obtenção de renda. A esta pesquisa qualitativa foi associado o posicionamento de legisladores especialistas em inclusão social. Foram analisadas as reservas legais de vagas, as adaptações no ambiente de trabalho, as fontes de recrutamento e as dificuldades para inserção ao mercado. Os resultados permitiram constatar a dificuldade das PcD em conseguirem colocação no mercado de trabalho, principalmente pelo preconceito, observado nos processos seletivos, assim como no perfil das vagas oferecidas. Por parte das empresas, pode-se observar preocupação com a elevação dos custos na contratação e a alta rotatividade. Os especialistas reconhecem a deficiência de capacitação dos deficientes visuais para o mercado, a falta de conexão destes com as empresas e a timidez empresarial para o cumprimento da cota legal, visando à inclusão. Pode-se concluir que, mesmo após 25 anos da legislação inclusiva, ocorre urgente necessidade de atualização das políticas públicas em relação às empresas, na valorização das PcD, conforme recomendado no ODS 8 da Organização das Nações Unidas (ONU).
\end{abstract}

Palavras-chave: pessoa com deficiência visual; mercado de trabalho; Rio de Janeiro.

Abstract: The article aims to outline the profile of a sample of the population with disabilities (PwD), specifically visual impairments, and private sector companies that hire PwD in the city of Rio de Janeiro, in order to obtain subsidies for the improvement of public policies that guarantee this social group the right to obtain income. This qualitative research was associated with the position of legislators specialized in social inclusion. Legal reserves of vacancies, adaptations in the work environment, sources of recruitment, and difficulties in entering the market were analyzed. The results allowed verifying the difficulty of the PwD in obtaining placement in the job market, mainly due to the prejudice, observed in the selection processes, as well as in the profile of the vacancies offered. On the part of the companies, it is possible to observe concern with the increase in costs in hiring and the high turnover. The specialists recognize the lack of training of the visually impaired for the market, the lack of connection with the companies, and the shyness of the company to comply with the legal quota, aiming at inclusion. It can be concluded that, even after 25 years of inclusive legislation, there is an urgent need to update public policies concerning companies, in the valorization of PWD, as recommended in SDG 8 of the United Nations (UN).

Keywords: person with disabilities; job market; Rio de Janeiro.

Resumen: El artículo tiene el objetivo de esbozar el perfil de una muestra de la población con discapacidad $(P C D)$, específicamente discapacidad visual, y empresas del sector privado que contratan PcD en la ciudad de Rio de Janeiro, con el fin de obtener subsidios para la mejora de las políticas públicas que garantizan a este grupo social el derecho a obtener ingresos. Esta investigación cualitativa se asoció con la posición de los legisladores especializados en inclusión social. Se analizaron las reservas legales de vacantes, las adaptaciones en el entorno laboral, las fuentes de contratación y las dificultades para ingresar al mercado. Los resultados mostraron la dificultad de PcD para conseguir un trabajo, principalmente debido a los prejuicios observados en

\footnotetext{
${ }^{1}$ Centro Universitário Augusto Motta (UNISUAM), Rio de Janeiro, Rio de Janeiro, Brasil.
} 
los procesos de selección, así como en el perfil de las vacantes ofrecidas. Por parte de las empresas, es posible observar preocupación por el aumento de los costos en la contratación y la alta rotación. Los especialistas reconocen la falta de capacitación para los discapacitados visuales en el mercado, la falta de conexión con las empresas y la timidez comercial para cumplir con la cuota legal, con el objetivo de incluirlos. Se puede concluir que, incluso después de 25 años de legislación inclusiva, existe una necesidad urgente de actualizar las políticas públicas en relación con las empresas, en la valorización de PcD, como recomienda en el ODS 8 de la Organización de las Naciones Unidas (ONU).

Palabras clave: persona con discapacidad visual; mercado de trabajo; Rio de Janeiro.

\section{INTRODUÇÃO}

Definir deficiência é uma tarefa difícil e, historicamente, o conceito em relação às pessoas com deficiência (PCD) foi tratado, ao longo do tempo, de modo impreciso e num processo descontínuo e heterogêneo, variando de um lugar para o outro, até mesmo dentro de um mesmo período histórico. De modo geral, observam-se indícios que apontam para uma realidade de exclusão social das pessoas com deficiência, seja por elas não poderem defender o grupo social a que pertenciam, como em Esparta, seja por representarem um custo para o Estado, como em Atenas, entre outros exemplos de situações de exclusão social (SILVA, 1987).

Existem registros do início da era Pós-Industrial, na Inglaterra (1760) e na França (1789), da contratação, além da mão de obra feminina e infantil, de pessoas com deficiência, podendose associar a estas três classes de trabalhadores o fato da necessidade de mão de obra barata, atrelado às condições de trabalho insatisfatórias para os parâmetros atuais. Contudo, ressalta-se a importância deste registro como sendo um primeiro passo inclusivo no trabalho, influenciando a percepção de que as PcD poderiam exercer um trabalho produtivo (PAIVA; BENDASSOLLI, 2017).

A Lei 8.213/91, Lei de Cotas (BRASIL, 1991), concretiza a inclusão social, em especial na inserção de pessoas com deficiência no trabalho, respondendo aos esforços de diversos atores sociais no amplo movimento em busca dos direitos à inclusão (FRANÇA; PAGLIUCA, 2009; GARCIA, 2014). Por outro lado, o papel fundamental da Lei foi, além de assegurar o direito ao trabalho para as $\mathrm{PcD}$, enfrentar o preconceito, dando visibilidade da capacidade produtiva desta mão de obra (TOLDRÁ, 2009; SIMONELLI; JACKSON FILHO, 2017).

A deficiência visual é a limitação sensorial capaz de atingir uma gravidade a ponto de praticamente anular a capacidade de ver, abrangendo vários graus de acuidade visual (ALEXANDRINO et al., 2016). No Brasil, existem mais de 6,5 milhões de pessoas com este tipo de deficiência, correspondendo à a proximadamente 500 mil pessoas com cegueira total e 6 milhões com baixa visão² (IBGE, 2010).

Por outro lado, do total da população brasileira, 23,9\% declararam ter algum tipo de deficiência, sendo a mais comum a visual, atingindo 3,5\% da população, seguida por problemas motores (2,3\%), intelectuais $(1,4 \%)$ e auditivos (1,1\%). No que tange particularmente ao Sudeste, onde o município do Rio de Janeiro está situado, 3,1\% da população tinha deficiência visual (IBGE, 2010).

Neste sentido, foi verificado ainda que no Estado do Rio de Janeiro, aproximadamente, $60 \%$ dos municípios tinham entre $23,9 \%$ e $30 \%$ da população com alguma de deficiência. Quando

\footnotetext{
2 O Decreto n. 5.296/2004 prevê dois tipos de deficiência visual: cegueira e a baixa visão. A primeira é caracterizada pela acuidade visual igual ou menor que 0,05 no melhor olho, com a melhor correção óptica. E a segunda é definida pela acuidade visual entre 0,3 e 0,05 no melhor olho, com a melhor correção óptica; os casos nos quais a somatória da medida do campo visual em ambos os olhos for igual ou menor que 60우 ou a ocorrência simultânea de quaisquer das condições anteriores.
} 
se analisou somente o município do Rio de Janeiro, pôde-se observar entre $20,1 \%$ e $25 \%$ da população com algum tipo de deficiência (IBGE, 2010).

Embora a deficiência visual tenha ocupado a primeira posição das deficiências mapeadas no Censo Demográfico (IBGE, 2010) da população brasileira, a Relação Anual de Informações Sociais (RAIS, 2018) relata que essas pessoas com deficiência visual ocupam a terceira colocação no percentual do quantitativo de deficientes empregados, uma vez que as deficiências física, auditiva e visual, neste critério, corresponderam a, respectivamente, 47,3\%, 18\% e 15,2\%.

Com a difusão de políticas públicas, como a reserva legal de vagas (Artigo 93 da Lei n. 8.213/1991) e a Lei Brasileira de Inclusão (Lei n. 13.146/2015), tornou-se evidente a resposta do Estado ao apelo da sociedade por inclusão da Pessoa com Deficiência $\left(\mathrm{PCD}^{3}\right)$ ao mercado de trabalho. Entretanto, embora a legislação determine a obrigatoriedade da contratação, nem sempre as empresas atendem às prescrições normativas, o que implica a aplicação recorrente de penalidades pelos órgãos de fiscalização e controle (SIMONELLI; JACKSON FILHO, 2017), sendo que esta prática torna o ingresso no mercado de trabalho ainda mais difícil para as pessoas com deficiência visual, em relação às outras (SILVA; PRAIS; SILVEIRA, 2015).

Pelo exposto, o presente artigo tem por objetivo traçar o perfil de uma amostra da população com deficiência visual e de empresas do setor privado que contratam PcD na cidade do Rio de Janeiro, visando obter subsídios para a melhoria de políticas públicas que garantam a este grupo social o direito de obtenção de renda, conforme recomendado no Objetivo de Desenvolvimento Sustentável (ODS 8) da Organização das Nações Unidas (ONU), que preconiza a promoção do crescimento econômico inclusivo e sustentável, com emprego pleno e produtivo, e trabalho decente para todos.

\section{A PESQUISA CIENTÍFICA}

\subsection{Procedimentos Metodológicos}

A pesquisa foi realizada no município do Rio de Janeiro, sendo de desenho qualitativo, com coleta de dados de deficientes visuais, empresas e especialistas. Para a coleta de dados, foram utilizados questionários como instrumento de aproximação, um elaborado para os participantes e outro para as empresas, compostos por questões abertas, fechadas e dependentes, segundo Gil (2010), e entrevistas estruturadas, seguindo roteiro previamente estabelecido, segundo Marconi e Lakatos (2002).

A pesquisa foi submetida ao Comitê de Ética em Pesquisa do Centro Universitário Augusto Motta e ao Comitê de Ética em Pesquisa da Faculdade de Medicina de Valença, responsável pela instituição coparticipante, o Instituto Benjamin Constant, sendo aprovada em ambos comitês, respectivamente, sob os pareceres n. 3.256.899, CAEE 10531519.0.0000.5235 e n. 3.311.590, CAEE 10531519.0.3001.5246.

Foram entrevistadas 20 pessoas com deficiência visual relacionadas ao Instituto Benjamin Constant, encontradas, de forma aleatória, no pátio da referida instituição. Quanto às empresas, somente oito dos 25 responsáveis do setor de recursos humanos de empresas privadas, também convidados pelo mesmo instituto, que disponibilizam vagas para PcD. Os respondentes tinham

\footnotetext{
${ }^{3}$ A expressão PcD (Pessoa com Deficiência) é invariável, conforme Manual de Redação Mídia Inclusiva do Rio Grande do Sul. Por exemplo, podem ser utilizados os termos: a PcD, as PcD, da PcD e das PcD.
} 
a partir de 18 anos de idade e foram excluídos os indivíduos incapazes de compreender ou responder aos questionamentos, bem como as empresas que não atuassem na cidade do Rio de Janeiro.

Participaram da pesquisa também dois especialistas, sendo convidados dois legisladores com conhecimento na área de inclusão de PcD no mercado de trabalho: um do Poder Legislativo federal e outro do municipal, o primeiro com formação acadêmica em Engenharia de Produção e Mestrado em Políticas Públicas (RIGONI, 2019), e o outro graduado em Serviço Social, com Especialização em Gestão Pública (NOVAES, 2019). Com isso, pretendeu-se compreender e explicitar as dificuldades e oportunidades existentes na aproximação entre oferta e demanda de vagas de trabalho para pessoas com deficiência visual na cidade do Rio de Janeiro.

Com base nos resultados obtidos, foram discutidas as principais barreiras enfrentadas, os avanços tecnológicos, as políticas públicas e outros meios relevantes para o fomento da inclusão das pessoas com deficiência visual no mercado de trabalho no município carioca.

\subsection{Consolidação dos Resultados}

Após a coleta dos dados, foi realizada a codificação das respostas e análise de conteúdo. Esses resultados retrataram uma análise qualitativa das empresas e das pessoas com deficiência visual que residem ou atuam na cidade do Rio de Janeiro. Para melhor pontuar os resultados da pesquisa, foram criadas as categorias temáticas que serão abordadas a seguir: contribuições fornecidas pelas pessoas com deficiência visual, pelas empresas e pelos especialistas.

Categoria 1: contribuições fornecidas pelas pessoas com deficiência visual

Com relação ao perfil da amostra da população com deficiência visual entrevistada (Tabela 1), composta por 20 (vinte) voluntários que aceitaram participar do estudo, é possível observar uma distribuição quase igualitária quanto ao gênero. Contudo, em relação à faixa etária, independentemente de gênero, pode-se observar uma maior atuação para a população em idade no auge da produtividade e com cegueira total.

Tabela 1 - Perfil dos Entrevistados com Deficiência Visual

\begin{tabular}{|c|c|c|c|c|c|}
\hline \multicolumn{3}{|c|}{ Sexo } & \multicolumn{3}{|c|}{ Idade } \\
\hline \multicolumn{2}{|l|}{$\begin{array}{l}\text { Mulheres } \\
\left(\mathrm{n}{ }^{*} \text { e } \% * *\right)\end{array}$} & $\begin{array}{l}\text { Homens } \\
\text { (n. e \%) }\end{array}$ & $\begin{array}{c}18 \text { a } 39 \text { anos } \\
(\text { n. e \%) }\end{array}$ & \multicolumn{2}{|c|}{$\begin{array}{c}\text { Acima de } 40 \text { anos } \\
(\text { n. e } \%)\end{array}$} \\
\hline \multicolumn{2}{|l|}{$9 / 45$} & $11 / 55$ & $16 / 80$ & & $4 / 20$ \\
\hline \multicolumn{3}{|c|}{ Formação } & \multicolumn{3}{|c|}{ Deficiência } \\
\hline $\begin{array}{l}\text { EnsinoFundamental } \\
\text { (n. e \%) }\end{array}$ & $\begin{array}{l}\text { Ensino Médio } \\
\qquad(\text { n. e \%) }\end{array}$ & $\begin{array}{c}\text { Ensino Profissional } \\
\text { (n. e \%) }\end{array}$ & $\begin{array}{c}\text { Ensino Superior } \\
\text { (n. e \%) }\end{array}$ & $\begin{array}{c}\text { Cegueira Total } \\
\text { (n. e \%) }\end{array}$ & $\begin{array}{c}\text { Baixa Visão } \\
\text { (n. e \%) }\end{array}$ \\
\hline $2 / 10$ & $9 / 45$ & $2 / 10$ & $7 / 35$ & $14 / 70$ & $6 / 30$ \\
\hline
\end{tabular}

*n. = número de participantes da amostra de pessoas com deficiência visual entrevistadas.

$* * \%=$ percentual correspondente da amostra de pessoas com deficiência visual entrevistadas.

Fonte: Elaboração dos autores, 2020.

Com relação à situação de empregabilidade, 10 participantes (50\%) trabalhavam; contudo, destes entrevistados empregados, oito (80\%) afirmaram não terem sido promovidos. Quem não 
estava inserido foi questionado se estava em busca de oportunidades no mercado de trabalho, 14 voluntários (70\%) responderam estar à procura e seis (30\%) disseram não estar à procura em razão do recebimento do Benefício de Prestação Continuada (BPC).

Ao serem indagados, 17 participantes (85\%) alegaram ter dificuldades para colocação no mercado de trabalho. O primeiro motivo apontado por oito entrevistados foi a ausência de políticas empresariais para contratação de PcD, correspondendo a 40\% da população amostral, seguido de insatisfação com perfil das vagas oferecidas, relatada por seis voluntários, correspondendo a 30\% dos entrevistados. Já a ausência de qualificação ou experiência foi a resposta de três participantes, correspondendo a $15 \%$ da população amostral. Com relação às dificuldades para participação em processos seletivos, 11 voluntários, ou seja, mais da metade dos entrevistados (55\%) informaram terem enfrentado problemas, tendo a maioria apontado as barreiras físicas ou arquitetônicas, como a ausência de sinalização em braile ou piso tátil.

Para $50 \%$ dos entrevistados, a visão sobre a atuação do RH nas empresas quanto à PcD é negativa, considerando estarem despreparados ou muito despreparados. Ao referir-se a um processo do qual participou, a PcD n. 7 lamentou: "A gente chega lá e a pessoa não sabe o que fazer, como lidar".

No que diz respeito à ciência sobre a reserva legal de vagas, 75\% (15 participantes) afirmaram conhecê-la parcialmente. Segundo suas percepções, para 95\%, ou seja, 19 entrevistados, as empresas contratam a PcD somente para cumprir a lei, e não com uma visão de resgate dos direitos à cidadania.

Ao perguntarmos sobre quais medidas poderiam ser adotadas para apoiar a inserção profissional da PcD, os entrevistados apontaram, com destaque: adaptações nas estações de trabalho, criação de plataformas acessíveis para divulgação de oportunidades e ampliação da oferta de formação profissional específica.

O preconceito é vivenciado pelas pessoas com deficiência, porém tornou-se mais evidente quando se trata da deficiência visual, conforme relatado pelo PcD n. 5: "A gente vê muita vaga para deficiente [...] quando sabem que o candidato é cego, você fica de lado, seu currículo nem é avaliado".

A totalidade dos entrevistados respondeu se informar sobre oportunidades de trabalho, 15 deles (65\%) em sites especializados; três participantes (15\%) em redes sociais; três (15\%) por indicações; e somente um entrevistado (5\%) mencionou as instituições de ensino e reabilitação.

Em relação ao conhecimento sobre a legislação, 15 participantes (75\%) responderam conhecer parcialmente a Lei n. 8.213/1991, denominada Lei de Cotas (BRASIL, 1991), sendo que dois participantes (10\%) da amostra populacional estudada se manifestaram como profundos conhecedores da referida lei.

Categoria 2: contribuições fornecidas pelas empresas

Embora 25 empresas do Rio de Janeiro tenham sido convidadas para participar da pesquisa, apenas oito responderam ao questionário. Todas estas instituições responderam que tinham funcionários com deficiência em seu quadro e, em cinco destas, ou seja, 62,5\% das que retornaram o questionamento, havia funcionários com deficiência visual, sendo 17\% com baixa visão e $83 \%$ com cegueira total, em relação ao quantitativo da reserva legal de vagas (Lei no. 8.213/1991) e da Lei Brasileira de Inclusão (Lei no. 13.146/2015). 
Indagadas sobre a reserva legal de vagas, quatro (50\%) das instituições que responderam declararam cumpri-la integralmente e duas (25\%) destas empresas declararam cumpri-la parcialmente, porém os outros $25 \%$, ou seja, duas empresas, informaram o descumprimento.

Em relação à conexão das empresas com as pessoas com deficiência visual, seis destas, ou seja, 30\%, informaram que utilizam como forma de captação de funcionários com deficiência as instituições de ensino e reabilitação, os sites de emprego e outras fontes.

Ao analisar a produtividade e o desempenho dos funcionários com deficiência, as empresas, em sua totalidade, indicaram pontos positivos, tais como: motivação para os demais funcionários, eliminação do preconceito, ambiente de trabalho mais humanizado e fortalecimento do espírito de equipe. No tocante aos aspectos negativos, apontaram aumento de custos e da rotatividade de pessoal.

Categoria 3: contribuições fornecidas pelos especialistas

Dois parlamentares com conhecimento na área da inclusão da PcD participaram da pesquisa, o deputado federal Felipe Rigoni e a vereadora do Rio de Janeiro Luciana Novaes. Felipe Rigoni é o primeiro deputado federal com deficiência visual eleito, tem formação em Engenharia de Produção e Mestrado em Políticas Públicas (RIGONI, 2019). Luciana Novaes foi vítima de uma bala perdida no Rio de Janeiro que a tornou tetraplégica (NOVAES, 2019). Tem formação em Serviço Social e Pós-Graduação em Gestão Pública.

O deputado Felipe Rigoni afirmou que a reserva de vagas é apenas um instrumento e, para que seja cumprida de forma coerente, é preciso que os dois principais obstáculos enfrentados pela PcD sejam resolvidos, quais sejam: que os deficientes estejam capacitados e que haja conexão entre empresas contratantes e os deficientes, sendo esse o principal obstáculo para a inclusão laboral do deficiente.

A vereadora pontuou que os principais obstáculos são problemas relacionados à falta de acessibilidade, tanto em impedimentos físicos quanto em dificuldades de comunicação com pessoas com deficiência visual. No tocante à reserva legal de vagas, embora tenham ocorrido modificações positivas no decorrer da história, ainda não foi alcançado o patamar ideal para a inclusão.

\section{DISCUSSÃO SOBRE OS RESULTADOS DA PESQUISA}

Durante a pesquisa, tornou-se evidente que, no Rio de Janeiro, existe dificuldade para integração das pessoas com deficiência visual ao mercado de trabalho. Após analisar as informações apuradas na coleta de dados, e cruzando as respostas fornecidas, foram apurados três pontos que merecem destaque, os quais serão abordados a seguir: as principais barreiras enfrentadas pelas pessoas com deficiência visual e pelas organizações; as políticas públicas e a reserva legal de vagas; e as possibilidades para aproximação entre as empresas e a PcD.

\subsection{As principais barreiras enfrentadas pelas pessoas com deficiência visual e pelas organizações}

Os achados neste estudo, encontrados na amostra populacional avaliada, em relação ao perfil das pessoas com deficiência visual e sua inserção no mercado de trabalho, concordaram com 
Burchert, Oliveira e Ziliotto (2018) quando afirmaram que o sentido do trabalho para as pessoas com deficiência envolve questões como sobrevivência, ser útil à sociedade como trabalhadores e pessoalmente. Ainda sobre este tema, Zeferino (2019) ressalta que os direitos das pessoas com deficiência apresentam problemática desde os tempos remotos, até os dias atuais, visto que a sociedade ainda contempla a deficiência como uma incapacidade, havendo uma impertinência grosseira em razão do preconceito com que ainda são obrigados a conviverem.

Quanto ao percurso de formação intelectual do grupo estudado, pode-se observar que existe um contingente de pessoas com deficiência visual, em idade produtiva, com qualificação para o ingresso ou reingresso no mercado de trabalho. Os dados obtidos permitem inferir que este processo poderia ser mais amplo e contínuo se não fossem as barreiras sociais, principalmente o preconceito, corroborando Silva, Prais e Silveira (2015) quando concluíram que o preconceito e a discriminação representam grande entrave à inclusão, dificultando a contratação de pessoas com deficiência pelas empresas privadas, que classificam esta ação como um complicador na relação com o cliente. Neste sentido, Simonelli e Jackson Filho (2017) relataram que, na empresa, esta conduta pode ser verificada na postura da organização ao excluir as deficiências consideradas mais severas da contratação; na atitude dos gestores ao indicarem vagas com pouca complexidade para preenchimento pela $\mathrm{PCD}$ e na conduta dos colegas ao tratarem com indiferença outros funcionários com deficiência.

No presente estudo, ficou clara, pelos depoimentos dos deficientes visuais que trabalham, a dificuldade que estes têm em alcançarem planos de carreira ou promoções nas empresas, demonstrando a defasagem das organizações em implementar medidas inclusivas e adotar planos de carreiras extensivos a todos os funcionários, abarcando as pessoas com deficiência. Sobre este fato, Gil (2002) já destacava a necessidade de as empresas desenvolverem programas de recrutamento, seleção, contratação e desenvolvimento da $\operatorname{PcD}$, sendo que a eficácia da inclusão desses profissionais na empresa depende do compromisso firme da direção com este processo, de forma que o combate explícito às manifestações preconceituosas, o acompanhamento, a adaptação e o respeito para com os novos funcionários envolvem a empresa como um todo na responsabilidade social de inclusão.

Ainda sobre o papel desenvolvido pela empresa em relação à $\mathrm{PcD}$, convém destacar a relevância da capacitação adequada dos recursos humanos, pois se pode observar neste estudo a falta, nas empresas, de programas promotores da autoestima e da inserção de pessoas com deficiência visual nas relações sociais, a fim de proporcionar pleno exercício de cidadania e geração de renda com segurança.

A visão sobre a atuação do RH nas empresas quanto à PcD é negativa, considerando estarem despreparados ou muito despreparados. Esta foi a opinião colhida nesta pesquisa, em que as PcD enfrentaram dificuldades para participar de processos seletivos, com maior recorrência para barreiras físicas e arquitetônicas, como ausência de sinalização em braile ou piso tátil.

No tocante ao trabalho da $\mathrm{PCD}$, as empresas apontaram dificuldades relacionadas à rotatividade de pessoal e ao aumento dos custos de contratação. Os investimentos em acessibilidade são extremamente vantajosos para a PcD e para a empresa, além disso, o acréscimo de custo para construir seguindo parâmetros de desenho universal ${ }^{4}$ é de menos de $5 \%$ e os

\footnotetext{
${ }^{4} \mathrm{O}$ art. 3o da Lei Brasileira de Inclusão (LBI) conceitua desenho universal como "concepção de produtos, ambientes, programas e serviços a serem usados por todas as pessoas, sem necessidade de adaptação ou de projeto específico, incluindo os recursos de tecnologia assistiva".
} 
benefícios são muitos se comparados aos gastos, como a melhora da imagem da organização, maior integração e aumento de produtividade, beneficiando outros grupos, não somente a PcD, como pessoas obesas, cardíacas, gestantes, crianças e idosos (INSTITUTO ETHOS, 2002).

\subsection{As políticas públicas e a reserva legal de cargos}

No contexto local do Rio de Janeiro, foram verificadas algumas políticas públicas, como as Leis n. 3.167/2000, que prevê passe livre municipal à PcD, e a Lei n. 6.268/2017, que define critérios para instalação dos leitores de cartões nos ônibus do município do Rio de Janeiro, facilitando a utilização por pessoas com deficiência visual. Na mesma localidade, existem, ainda, programas e instituições voltados à PcD, com destaque para o Instituto Benjamin Constant (IBC) e a Secretaria Municipal da Pessoa com Deficiência e Tecnologia do Rio de Janeiro (SMDT). Ambas instituições têm programas de capacitação e dispõem de laboratórios de tecnologia assistiva, o que facilita o aprendizado pelas pessoas com deficiência visual.

Ao analisar a evolução da legislação e das políticas sociais por meio de pesquisa desenvolvida no presente trabalho, foi possível perceber a preocupação das pessoas com deficiência visual em conhecer os seus diretos, principalmente a Lei n. 8.213/1991, que os permite alcançar o mercado de trabalho, o que não significa plena aplicabilidade das referidas regras.

Cabe ressaltar que as empresas que tenham acima de 100 funcionários e não obedeçam ao cumprimento da reserva legal de vagas estarão sujeitas à fiscalização pelo Ministério do Trabalho e Emprego ${ }^{5}$, conforme Artigo $36 \S 5$ o do Decreto n. 3.298/1999, podendo incorrer no pagamento de multas que variam de $\mathrm{R} \$ 2.441,28$ até o teto por recorrência (que pode chegar a $R \$ 241.126,88)$, segundo a Portaria Interministerial n. 09/2019 (BRASIL, 2019).

Outro ponto importante é o Benefício de Prestação Continuada (BPC), política assistencial também observada no decorrer da pesquisa. A recusa pela inserção no mercado pode ser motivada pelo receio da perda do benefício, que ocorre quando a PcD exerce atividade profissional remunerada. Como constatado por Araújo, o medo pode motivar que muitas pessoas se abstenham de tentar uma colocação formal, o que demonstra um problema para aplicação do Artigo 93 da Lei 8.213/91, Lei das Cotas, causado pela falta de segurança do trabalhador PcD na empresa que o contrata somente para cumprimento da lei, e não por reconhecer a necessidade de inclusão social (ARAúJO, 2017).

No tocante à aplicabilidade das políticas públicas, é fundamental a existência de conexão entre as esferas federais, estaduais e municipais, a fim de que sejam criadas políticas sólidas, integradas, funcionais e duradouras. Além disso, é fundamental que haja estímulos para que as empresas contratem o deficiente por valorizar o perfil dos candidatos e para promover a inclusão, não apenas para evitar aplicação das penalidades pelo descumprimento.

\subsection{Possibilidades para aproximação entre empresas e a PcD}

A ausência de conexão entre as PcD desempregadas e as organizações que têm pendência quanto ao cumprimento das cotas também foi apurada na pesquisa. O deputado federal Felipe Rigoni acredita ser esse o principal obstáculo para a inclusão laboral do deficiente. Adicionalmente

\footnotetext{
${ }^{5}$ A partir de 10 de janeiro de 2019, o Ministério do Trabalho foi incorporado ao Ministério da Economia, conforme Medida Provisória n. 870, posteriormente convertida na Lei n. 13.844, de 18/06/2019. Entretanto, até o presente momento, não houve alteração da nomenclatura no Decreto n. 3.298/1999, por isso optou-se pela denominação utilizada nesta legislação.
} 
à análise do deputado, apurou-se inexistir um banco único de cadastro que aproxime a oferta e a demanda por oportunidades de trabalho para a PCD.

Na pesquisa, pode-se verificar total desencontro entre as PcD e as empresas. Há um ruído de comunicação entre potencial empregado e o empregador, e, numa época de globalização de informações, a existência deste hiato no recrutamento de pessoas que necessitam ingressar no mercado de trabalho causa estranheza.

Apesar dos avanços na legislação e nas políticas públicas, o número de pessoas com deficiência efetivamente inseridas no mercado de trabalho ainda é baixo no Rio de Janeiro. Esta adversidade, em especial quando analisamos a deficiência visual, é agravada, além do preconceito, pela ausência de informação das empresas e instituições.

As tecnologias assistivas podem ampliar as competências, funcionalidades e autonomia da PcD no mundo laboral (DEFENDI, 2016). Segundo o autor, esse recurso busca promover a inclusão social por meio de avanços tecnológicos e metodológicos que visem à construção de equipamentos, recursos e estratégias que potencializem habilidades.

No horizonte da deficiência visual, muitos recursos estão disponíveis para auxiliar a pessoa com cegueira total ou baixa visão, tais como: a) ampliadores de tela: são softwares que permitem ampliação dos elementos da tela. Exemplos: Lupa do Windows 10, Magic e Orca; b) leitores de tela: são softwares que fornecem informações por meio da síntese de voz, realizando, principalmente, a leitura dos elementos textuais. Exemplos: Dosvox, NVDA, Jaws e Virtual Vision; c) existem, ainda, impressoras em braile, scanners com voz, calculadora sonora, ponteiras de bengalas inteligentes, lupas manuais e de mesa (IBC, 2016; SONZA; SALTON; CARNIEL, 2016).

O aumento de custos para a contratação da PcD foi um dos pontos negativos relatados pelas organizações durante a pesquisa. Convém esclarecer que algumas dessas tecnologias listadas acima são gratuitas e de fácil utilização, como os softwares Dosvox, NVDA e Orca. Outros recursos, como lupas e bengalas, são utilizados pelos deficientes visuais em cotidiano, não implicando em custo adicional para a empresa.

Foi apurado que $40 \%$ das empresas realizaram adaptações tecnológicas, como disponibilização de software, leitor de tela, lupas e impressoras em braile. Como ponto de partida, este é um bom número por mostrar que algumas empresas estão atentas às necessidades dos funcionários com deficiência, mas muito ainda resta a ser feito para a efetiva inclusão. Além da utilização de tecnologias assistivas, é preciso analisar outras possibilidades, como o teletrabalho, também conhecido como home office ou trabalho remoto, que se difundiu graças à utilização de recursos de informática no cotidiano da população, também abrindo um excelente campo de trabalho para a PCD (SASSAKI, 2010).

Um novo instrumento que também pode auxiliar tanto os deficientes visuais quanto as empresas é o emprego "apoiado" ou "com apoio", no qual a PcD é treinada para desenvolver suas funções num processo conhecido como "colocar-treinar" (SASSAKI, 2010). Os referidos programas permitem que o trabalhador com deficiência seja colocado na empresa e treinado, receba assistência individual e constante, conforme exigido pela severidade e pelas particularidades de cada limitação (ARAúJO, 2017).

De forma equivocada, muitas organizações temem ausência de acessibilidade e, consequentemente, aumento dos custos, ocorrência de acidentes de trabalho ou mesmo dificuldades de adaptação ao grupo de trabalho. Porém as adaptações no ambiente de trabalho são necessárias e devem ser tratadas individualmente, pois cada PcD pode precisar de um ou 
outro recurso. Como destacado por Defendi (2016), a escolha do recurso mais apropriado dependerá das condições funcionais da pessoa com deficiência visual, visando diminuir ou eliminar as barreiras existentes. Por isso, é preciso que as empresas estejam atentas para o que cada funcionário necessita, de forma única.

Como observado, a participação da empresa é fundamental para que o deficiente visual seja efetivamente incluído no mundo laboral. A atuação das instituições pode ocorrer de diversas formas, seja num olhar mais atento para entender às necessidades do funcionário com deficiência, adotando a postura que melhor the atenda, seja tornando o ambiente mais acessível, adquirindo tecnologias assistivas que facilitem seu trabalho, implementando o emprego apoiado, adotando jornadas flexíveis ou teletrabalhos.

Ao analisarmos dados do IBGE (2010), percebe-se que, no Brasil, 46\% das pessoas entre 18 e 64 anos com deficiências severas eram deficientes visuais, o que corresponde ao primeiro lugar entre os tipos de deficiência considerados. No entanto, o país ocupou a terceira colocação quanto à empregabilidade da PcD (RAIS, 2018). Esses números demonstram a expressividade do número de deficientes visuais no Brasil e alertam para a existência de problemas relacionados à empregabilidade dessa modalidade de deficiência.

\section{CONSIDERAÇÕES FINAIS}

A pesquisa realizada com enfoque na cidade do Rio de Janeiro permitiu verificar que existem diversas dificuldades enfrentadas tanto pelas pessoas com deficiência visual quanto pelas organizações relacionadas a esta causa. Os obstáculos identificados como os de maior impacto foram: preconceito, ausência de políticas empresariais para contratação da PcD, atuação insatisfatória da área de recursos humanos das empresas, falta de acessibilidade e de acesso à educação e à capacitação. Pelas empresas, foi indicado, ainda, o aumento de custos gerado pela contratação das PcD. Além disso, foi pontuado também o distanciamento entre as PcD e as empresas.

A incapacidade das organizações de entenderem as necessidades dos candidatos, muitas vezes, impede que pessoas com cegueira total ou baixa visão consigam efetivamente participar de processos seletivos. Por isso, a atuação dos recursos humanos é de basilar importância no processo de inclusão. Além da capacitação dos profissionais dessa área, é necessária também a participação ativa dos gestores nesse processo, a fim de que a cultura inclusiva seja vivenciada por todos na empresa.

Durante as pesquisas, foi apurado avanço na legislação brasileira e na implementação de políticas públicas direcionadas à inclusão da pessoa com deficiência com enfoque para o encaminhamento profissional. Entretanto, apesar desse progresso, as empresas ainda encontram dificuldades para suprir as vagas destinadas à $\mathrm{PcD}$, como se pode observar no aumento dos autos de infração por descumprimento, além das dificuldades dos deficientes visuais para ingressarem no mercado de trabalho.

O investimento em capacitação profissional direcionada às necessidades do mercado e a criação de um banco de cadastro uniformizado que una as pessoas com deficiência e as empresas foram dois pontos de destaque nesta pesquisa. Ademais, para que haja capacitação e o pleno exercício do trabalho, devem ser feitos ajustes para que o ambiente de trabalho seja acessível, bem como sejam utilizadas tecnologias assistivas, como ampliadores e leitores de tela, para 
facilitar a autonomia e a independência pelo deficiente visual. Também, devem ser realizadas campanhas para reduzir preconceitos e informar a sociedade sobre a empregabilidade da PcD.

O processo de inclusão das pessoas com deficiência no mercado de trabalho não deve se resumir simplesmente à presença física do deficiente ocupando as vagas nas empresas, na forma de uma imposição ou custo para o empreendedor. Ao contrário, deve ser um meio para alavancar valor para ambas as partes envolvidas, de tal forma que a sinergia produzida por processos de trabalho bem estruturados, complementados por profissionais motivados e adequadamente posicionados, com e sem deficiência, em meio a um ambiente corporativo virtuoso e sem preconceitos, potencialize a adição de valor para o negócio, acionistas, clientes e partes interessadas. Desta forma, sob a perspectiva da PcD, a equidade, o desenvolvimento humano e a função social do trabalho tornam-se valores mais tangíveis e passíveis de realização, conforme recomendado no ODS 8 da Organização das Nações Unidas (ONU).

\section{REFERÊNCIAS}

ALEXANDRINO, Eduardo Gauze; SOUZA, Daiane; BLANCHI, Adriane Behring; MACUCH, Regiane; BERTOLINI, Sonia Maria Marques Gomes. Desafios dos alunos com deficiência visual no ensino superior: um relato de experiência. Cinergis, Santa Cruz do Sul, v. 18, n. 1, p. 1-7, 2016.

ARAÚJO, Josemar Figueiredo. Depois da Lei de Cotas: um estudo dos resultados da Política de Inclusão das Pessoas com Deficiência no mercado de trabalho. 2. ed. Rio de Janeiro: Josemar Araújo, 2017.

BRASIL. Ministério da Economia. Portaria Interministerial ME n. 9, de 15 de janeiro de 2019. Brasília, DF. Reajuste dos benefícios pagos pelo INSS e dos demais valores constantes do RPS. Brasília-DF, 2019. Disponível em: http://www.normaslegais.com.br/legislacao/portaria-me-9-2019.htm. Acesso em: 8 nov. 2019.

BRASIL. Lei n. 8.213, de 24 de julho de 1991. Dispõe sobre os Planos de Benefícios da Previdência Social. Brasília, DF, 1991. Disponível em: http://www.planalto.gov.br/ccivil_03/Leis/L8213cons.htm.htm. Acesso em: 8 out. 2018.

BURCHERT, Amanda; OLIVEIRA, Kelly; ZILIOTTO, Denise Macedo. Reflexões sobre a relação entre o percurso educacional e a empregabilidade de profissionais com deficiência visual. Canoas (RS): SEFIC, 2018.

CÂMARA DOS DEPUTADOS. Felipe Rigoni: bibliografia. Brasília: Câmara dos Deputados, 2019. Disponível em: https://www.camara.leg.br/deputados/204371/biografia. Acesso em: 29 out. 2019.

DEFENDI, Edson Luiz. Tecnologias assistivas e empregabilidade da pessoa com deficiência visual. Benjamin Constant, Rio de Janeiro, Edição especial, p. 87-96, 2016.

FRANÇA, Inacia Sátiro Xavier; PAGLIUCA, Lorita Marlena Freitag. Inclusão social da pessoa com deficiência: conquistas, desafios e implicações para a enfermagem. Revista da Escola de Enfermagem da USP, São Paulo, v. 43, n. 1, p. 178-85, 2009.GARCIA, Vinicius Gaspar. Panorama da inclusão das pessoas com deficiência no mercado de trabalho no Brasil. Trabalho, Educação e Saúde, Rio de Janeiro, v. 12, n. 1, p. 165-87, 2014.

GIL, Marta. O que as empresas podem fazer pela inclusão das pessoas com deficiência. São Paulo: Instituto Ethos, 2002. Disponível em: www.thos.org.br/uniethos/.../manual_pessoas_deficientes.pdf. Acesso em: 23 dez. 2019.

GIL, Antônio Carlos. Métodos e técnica de pesquisa social. 6. ed. São Paulo: Atlas, 2010. 
INSTITUTO BENJAMIN CONSTANT. O Encaminhamento do Deficiente Visual ao Mercado de Trabalho. Rio de Janeiro: IBC, 2016. Disponível em: http://www.ibc.gov.br/ component/ content/article?id=264. Acesso em: 18 set. 2019.

INSTITUTO BRASILEIRO DE GEOGRAFIA E ESTATÍSTICA. Comitê das Estatística Sociais. Relação Anual de Informações Sociais [RAIS]. Brasília-DF: IBGE, 2018. Disponível em: https://ces.ibge.gov.br/base-de-dados/ metadados/mte/relacao-anual-de-informacoes-sociais-rais.html. Acesso em: 14 maio 2021.

INSTITUTO BRASILEIRO DE GEOGRAFIA E ESTATÍSTICA. Censo demográfico. Rio de Janeiro: IBGE, 2010. Disponível em: https://censo2010.ibge.gov.br/resultados.html. Acesso em: 10 ago. 2019.

INSTITUTO ETHOS. O que as empresas podem fazer pela inclusão das pessoas com deficiência. Coordenação de Marta Gil. São Paulo: Instituto Ethos, 2002. Disponível em: https://www3.ethos.org.br/wp-content/ uploads/2012/12/25.pdf. Acesso em: 2 nov. 2019.

MARCONI, Marina de Andrade; LAKATOS, Eva Maria. Técnicas de pesquisa. 5. ed. São Paulo: Atlas, 2002.

NOVAES, Luciana. Biografia. Everybodywiki, Rio de Janeiro, 2019. Disponível em: https://pt.everybodywiki. com/Luciana_Novaes. Acesso em: 14 maio 2020.

PAIVA, Juliana Cavalcante Marinho; BENDASSOLLIL, Pedro F. Políticas sociais de inclusão social para pessoas com deficiência. Psicologia em Revista, Belo Horizonte, v. 23, n. 1, p. 418-29, 2017.

SASSAKI, Romeu Kazumi. Inclusão: construindo uma sociedade para todos. 8. ed. Rio de Janeiro: WVA, 2010.

SILVA, O. M. A epopeia ignorada: a pessoa deficiente na história do mundo de ontem e de hoje. São Paulo: CEDAS, 1987. 470 p.

SILVA, Priscila Neves-Silva; PRAIS, Fabiana Gomes; SILVEIRA, Andréa Maria. Inclusão da pessoa com deficiência no mercado de trabalho em Belo horizonte, Brasil: cenário e perspectiva. Ciência \& Saúde Coletiva, São Paulo, v. 20, n. 8, p. 2549-58, 2015.

SIMONELLI, Angela Paula; JACKSON FILHO, José Marçal. Análise da inclusão de pessoas com deficiência no trabalho após 25 anos da Lei de Cotas: uma revisão da literatura/Analysis of the inclusion of people with disabilities at work after 25 years of the publication of Brazilian Law of Quotas: a literature review. Cadernos Brasileiros de Terapia Ocupacional, São Carlos, v. 25, n. 4, p. 855-867, 2017.

SONZA, Andréa Poletto; SALTON, Bruna Poletto; CARNIEL, Everaldo. Tecnologia assistiva como agenda de inclusão de pessoas com deficiência visual. Benjamin Constant, Rio de Janeiro, Edição especial, p. 21-39, 2016.

TOLDRÁ, R. C. Políticas afirmativas: opinião das pessoas com deficiência acerca da legislação de reserva de vagas no mercado de trabalho. Revista de Terapia Ocupacional da USP, São Paulo, v. 20, n. 2, p. 110-7, 2009.

ZEFERINO, Mayra Vidal Martins. Inclusão de pessoas com deficiência no mercado de trabalho. 2019. 65 f. Monografia (Curso de graduação em Direito) - Centro Universitário Toledo, Araçatuba, SP, 2019.

\section{Sobre os autores:}

Meline Melegario Lima: Mestranda do Programa de Pós-Graduação Stricto Sensu em Desenvolvimento Local no Centro Universitário Augusto Motta (UNISUAM), Rio de Janeiro. Pós-Graduada em Direito da Administração Pública pela Universidade Federal Fluminense (UFF). 
Graduada em Direito pela Universidade Estácio de Sá (UNESA). Ocupação atual e instituição. E-mail: meline.lima.pesquisa@gmail.com, Orcid: http://orcid.org/0000-0002-6637-2857

Kátia Eliane Santos Avelar: Doutora em Ciências pela Universidade Federal do Rio de Janeiro (UFRJ). Docente e pesquisadora do Programa de Pós-Graduação em Desenvolvimento Local do Centro Universitário Augusto Motta, UNISUAM, Rio de Janeiro, RJ. E-mail: katia.avelar@gmail. com, Orcid: http://orcid.org/0000-0002-7883-9442

José Teixeira de Seixas Filho: Pós-Doutorado em Bioquímica e Enzimologia pelo Instituto de Biotecnologia Aplicada à Agropecuária da Universidade Federal de Viçosa (UFV), Minas Gerais, Brasil. Docente e pesquisador do Programa de Pós-Graduação em Desenvolvimento Local do Centro Universitário Augusto Motta (UNISUAM), Rio de Janeiro, RJ. E-mail: jseixas4@gmail.com, Orcid: http://orcid.org/0000-0002-5021-1290

Patricia Maria Dusek: Pós doutora em Justiça Constitucional pela Università di Pisa. Doutora em Direito pela Universidade Veiga de Almeida. Docente e Pesquisadora do Programa de PósGraduação em Desenvolvimento Local do Centro Universitário Augusto Motta, UNISUAM - Rio de Janeiro, RJ. E-mail: patricia.dusek@unisuam.edu.br, Orcid: http://orcid.org/0000-0003-3911-6943 
